\title{
Desenvolvimento de um projeto para construção de bomba-balão para contrapulsação aórtica
}

\author{
Celso Luiz dos REIS*, Paulo Roberto Barbosa ÉVORA*, José Carlos Franco BRASIL*, Paulo José de \\ Freitas RIBEIRO*, Adonis Garcia OTAVIANO*, Hércules Lisboa BONGIOVANI*, Rúbio BOMBONATO*, \\ Marcus Antônio FEREZ*, Ricardo Nilsson SGARBIERI*, Francisco Fernandes MOREIRA NETO*, Almir \\ Sales PEREIRA*, Percival GOMES*
}

RBCCV 44205-95

\begin{abstract}
REIS, C. L.; ÉVORA, P. R. B.; BRASIL, J. C. F.; RIBEIRO, P. J. F.; OTAVIANO, A. G.; BONGIOVANI, H. L.; BOMBONATO, R.; FEREZ, M. A.; SGARBIERI, R. N.; MOREIRA NETO, F. F.; PEREIRA, A. S.; GOMES, P. - Desenvolvimento de um projeto para construção de bomba-balāo para contrapulsação aórtica. Rev. Bras. Cir. Cardiovasc., 4(3): 210-219, 1989.

RESUMO: $O$ presente trabalho tem por finalidade apresentar as etapas de um projeto para construçăo de uma bomba-balão para contrapulsação aórtica. Desenvolveram-se três protótipos, sendo que os dois primeiros utilizavam ar comprimido e vácuo hospitalares para insuflação e deflação do cateter-balāo. Esses dois protótipos apresentavam como diferenças fundamentais: o tipo de dispositivo que captava o sinal luminoso da onda R do ECG utilizado para a sincronizaçāo do bombeamento; o tipo de válvula solenóide e os componentes eletrônicos de maior resolução utilizados no segundo protótipo. O terceiro e atual protótipo passou a obter o sinal da onda R diretamente da saída de cardioversão do monitor de ECG e substituiu o ar comprimio e o vácuo hospitalares, além das válvulas solenóides, por uma bomba eletromagnética. Está em fase de resolução o problema de deflaçāo tardia que ainda ocorre no sistema.
\end{abstract}

DESCRITORES: balāo intra-aórtico; contrapulsação; circulaçăo assistida, mecânica.

\section{INTRODUÇĀO}

O tratamento sistemático das complicaçōes do infarto agudo do miocárdio (IAM) nas unidades coronarianas diminuiu, sensivelmente, a mortalidade por arritmias cardiacas. Por outro lado, a terapêtica racional da insuficiência cardíaca, atuando-se na contratilidade, pré-carga e pós-carga cardíacas por meio da associaçāo de cardiotônicos e vasodilatadores sistêmicos, melhorou o prognóstico da falência aguda de bomba que se desenvolve durante a evolução de um IAM e no pós-operatório da cirurgia cardiaca. Porém o choque cardiogênico durante - IAM e as síndromes de baixo débito cardiaco pós-operatório têm, ainda, mortalidade inaceitavelmente alta. No sentido de mudar-se essa história natural, têm-se buscado modalidades terapêuticas de maior alcance, ocupando um lugar de destaque as técnicas e sistemas de assistência circulatória mecânica. A contrapulsação com o balão intra-aórtico desenvolveu-se, simultaneamente, com a aplicação dos conceitos atuais sobre função ventricular e circulação periférica e com a cirurgia cardiovascular contemporânea. Até hoje, apesar de suas limitações, tem sido o único método de assistência circulatória amplamente utilizado em todo o mundo ${ }^{3}$.

Embora sofisticados, os equipamentos atuais para bombeamento de cateter-balão intra-aórtico são aplicaçōes de princípios eletrônicos relativamente simples.

\footnotetext{
Trabalho realizado no Hospital do Coração de Ribeirão Preto. Fundação Dr. Waldemar B. Pessôa. Ribeirão Preto, SP, Brasil.

Apresentado ao 16: Congresso Nacional de Cirurgia Cardiaca. Sảo Paulo, SP, 7 e 8 de abril, 1989.

- Do Hospital do Coração de Ribeirāo Preto. Fundaçāo Dr. Waldemar B. Pessóa.

Endereço para separatas: Celso Luiz dos Reis. Av. Cândido Pereira Lima n: 1010, Jardim Recreio. 14.100 Ribeiråo Preto, SP, Brasil.
} 
REIS, C. L.; ÉVORA, P. R. B.; BRASIL, J. C. F.; RIBEIRO, P. J. F.; OTAVIANO, A. G.; BONGIOVANI, H. L.; BOMBONATO, R.; FEREZ, M. A.; SGARBIERI, R. N.; MOREIRA NETO, F. F.; PEREIRA, A. S.; GOMES, P. - Desenvolvimento de um projeto para construçāo de bomba-balão para contrapulsação aórtica. Rev. Bras. Cir. Cardiovasc., 4(3): 210-219, 1989.

Dessa forma, utilizando a experiência clínica do grupo, que confirmou o conceito da importância do uso do balão intra-aórtico em síndromes de baixo débito cardíaco, IAM per-operatório e ressecçāo de grandes aneurismas ventriculares, iniciou-se um projeto de construção de uma bomba-balāo para contrapulsação aórtica diastólica ECG-sincronizada 1 .

Cumprindo a finalidade de toda Instituição médica, que é a de associar o ensino e a pesquisa à assistência, acreditamos que os conhecimentos obtidos durante 0 desenvolvimento deste projeto possam vir a contribuir para a cirurgia cardiovascular, do ponto de vista tecnológico e científico, em âmbito nacional. Este é o objetivo deste trabalho.

\section{MATERIAL E MÉTODOS}

O ponto de partida para o início do projeto foi o primeiro modelo para contrapulsaçāo com balăo intraaórtico construido por MOULOPOULOS et alii ${ }^{4}$, em 1962.

O primeiro protótipo (Figura 1) utilizava, como força motriz para o movimento do fluído, o ar comprimido e o vácuo hospitalares aplicados ao cateter-balāo, indiretamente, através de uma câmara de segurança, para evitar-se a rotura acidental do balāo intra-aórtico. Esse câmara consistia em um bulbo de borracha acondicionado em recipiente rígido que recebia as variaçōes de pressẫo aspirando ou expulsando o seu conteúdo para o cateterbalão. Nessa fase, o projeto inclui a fabricação própria de um solenóide de núcleo deslizante com caracteristicas tais que permitia a insuflação e a desinsuflação do cateter-balāo. Para a contrapulsação diastólica com a onda R do ECG, utilizou-se um sensor foto-elétrico (LDR - Light Dependet Resistor) que captava o sinal luminoso externo da onda $R$ presente na maioria dos monitores de ECG. Desenvolveu-se, concomitantemente, o circuito eletrônico do sistema. O sinal luminoso captado pelo sensor foto-elétrico ligava, por meio de uma chave eletrônica transistorizada, um circuito temporizador que permitia que o rápido lampejo do sinal luminoso da onda $R$ do monitor fosse transformado em sinal eletrônico de duraçāo ajustável. Esse sinal comandava o funcionamento de outra chave eletrônica que, ao recebê-lo, energizava a válvula solenóide de três vias, a qual permitia a alternância em sua saída de pressāo positiva da rede hospitalar de ar comprimido com pressão negativa a partir da rede de vácuo. Ao sinal da onda $R$, que corresponde à sístole ventricular, o circuito eletrônico permitia que o balâo conectado à saída da válvula solenóide entrasse em rápida deflação pela linha ligada a vácuo. Cessado o sinal elétrico, a chave eletrônica desligava a válvula cortando a sucção em sua saída que, nessa condição, estava direcionada para o fluxo de ar comprimido que insuflava o balão na diástole. $\mathrm{O}$ controle do circuito temporizador permitia escolher o momento do ciclo cardíaco em que a insuflação deveria ocorrer, insuflação esta nunca coincidente com a onda R do ECG, pois, nessa condição, a vávula solenóide aplicava uma sucção ao balão. Nesse período, utilizou-se, para monitorização das ondas de pulso e contrapulso, um monitor Emai de três canais (ECG e Pressão).

O segundo protótipo usava, fundamentalmente, o mesmo circuito eletrônico, porém com componentes de

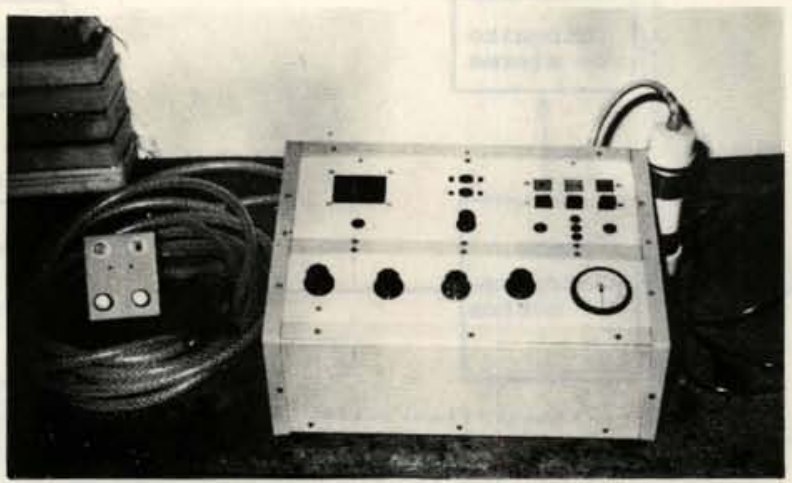

Fig. 1 - Fotografia da Protótipo I (1980) da bomba-balão para contrapulsaçâo aórtica.

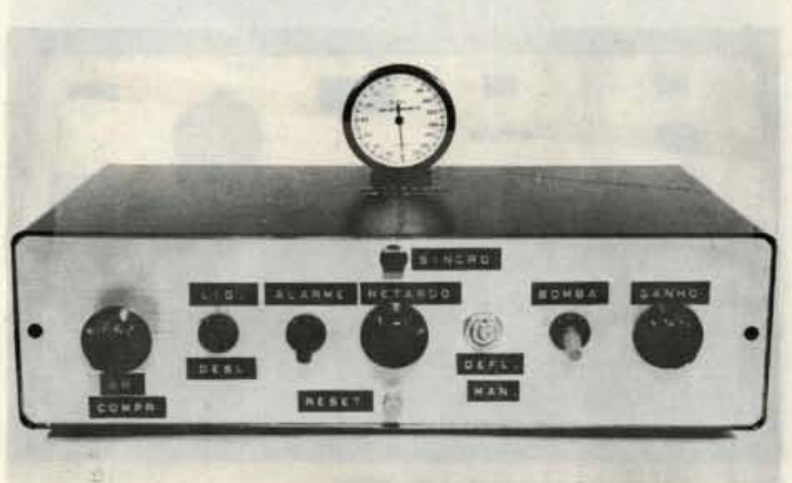

Fig. 2 - Fotografia do Protótipo II (1986-1987).

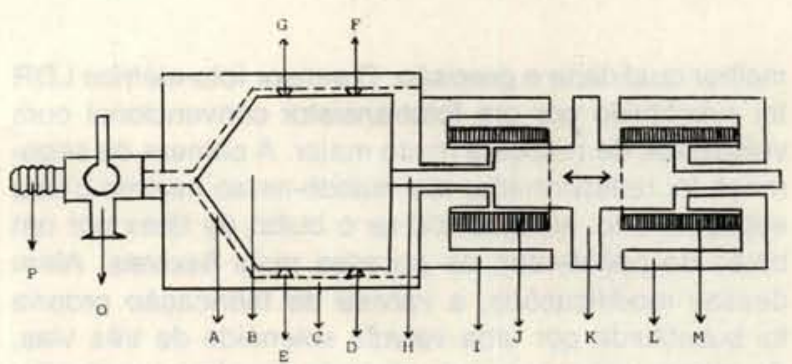

Fig. 3 - Diagrama esquematico da bomba eletromagnética tipo pistâo do Protótipo III (1988). A: câmara de bombeamento; B: pistão; C: camisa; D, E, F e G: anéis de vedaçăo (fixos à camisa e não ao pistão): $\mathrm{H}$ : eixo do pistâo: I: eletro-imả de insuflaçâo: $\mathrm{J}$ : bobina do eletro-imâ $\mathrm{I} ; \mathrm{K}$ : armadura comum a ambos os eletro-ímăs (comanda os movimentos do pistão); L: eletro-imã de deflação: $M$ : bobina de eletro-imã L; O: torneira de três vias; $\mathrm{P}$ : conexão ao cateter-balăo. 
REIS, C. L.; ÉVORA, P. R. B.; BRASIL, J. C. F.; RIBEIRO, P. J. F.; OTAVIANO, A. G.; BONGIOVANI, H. L.; BOMBONATO, R.; FEREZ, M. A.; SGARBIERI, R. N.; MOREIRA NETO, F. F.; PEREIRA, A. S.; GOMES, P. - Desenvolvimento de um projeto para construção de bomba-balāo para contrapulsaçāo aórtica. Rev. Bras. Cir. Cardiovasc., 4(3): 210-219, 1989.

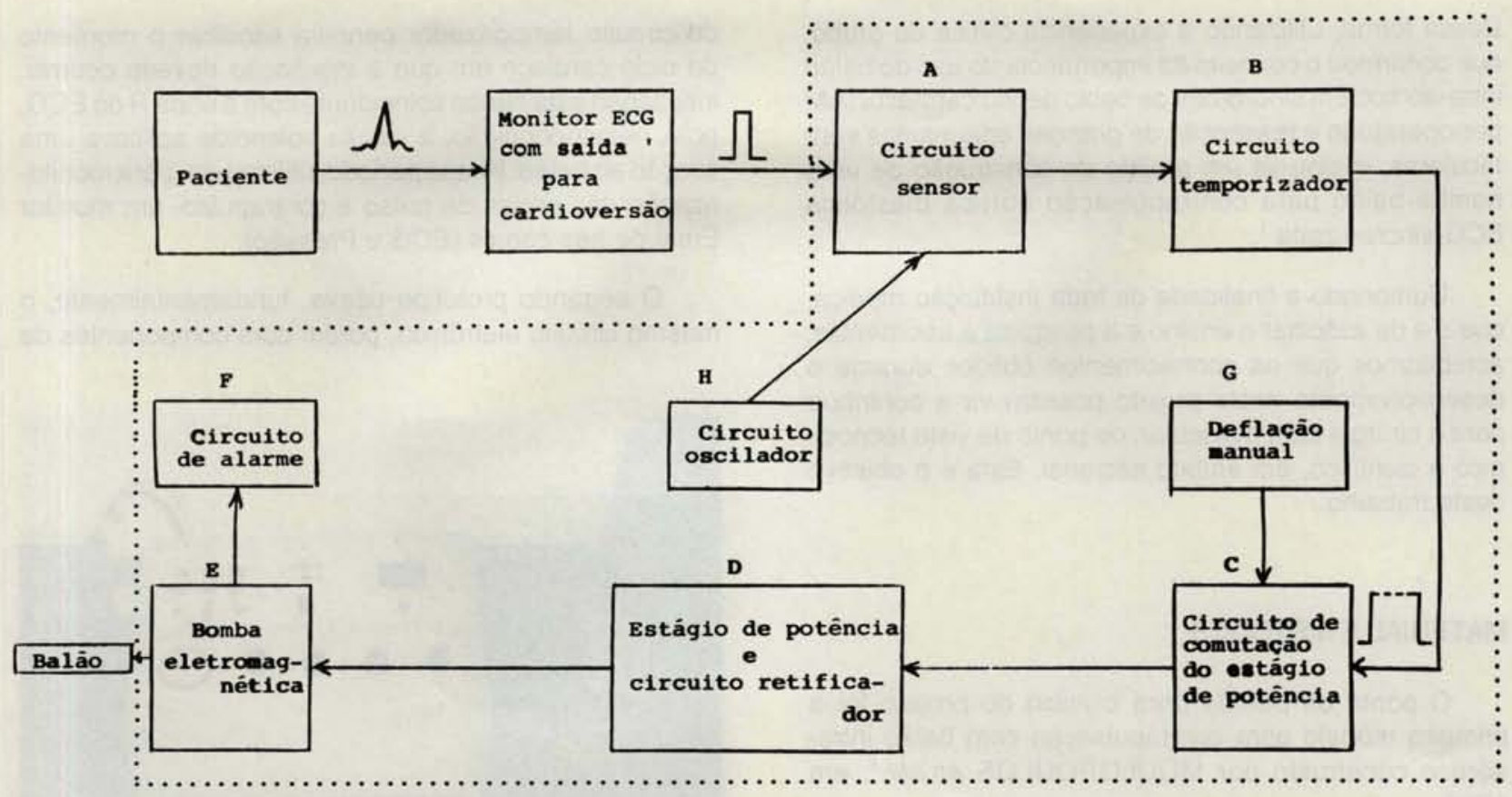

Fig. 4 - Diagrama em blocos do Protótipo III (1988).

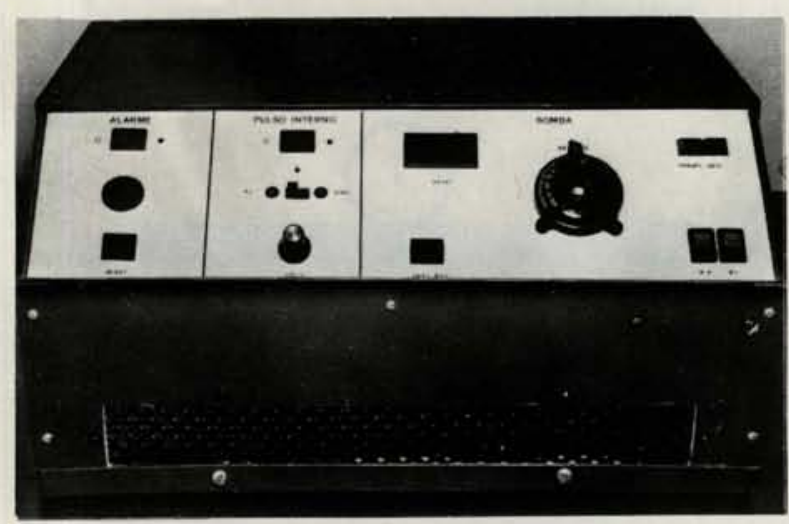

Fig. 5 - Fotografia do Protótipo III (1989).

melhor qualidade e precisão. O sensor foto-elétrico LDR foi substituido por um fototransistor convencional com velocidade de resposta muito maior. A câmara de segurança foi redesenhada, diminuindo-se ao mínimo o seu espaço morto, substituindo-se o bulbo de látex por um balāo de poliuretano de paredes mais flexíveis. Além dessas modificações, a válvula de fabricação própria foi substituída por uma válvula solenóide de três vias, de menor volume e que oferecia excelente vedação, sendo disponivel no comércio (Schrader-Bellows-BAzU). Como monitor, utilizou-se um aparelho computadorizado mais sofisticado, com três canais e recursos para a medida de débito por termodiluição (Honeywell-RM 300). Esse segundo protótipo encontra-se representado na Figura 2.
No terceiro protótipo, que corresponde ao atual estágio do desenvolvimento do projeto, o sinal sistólico captado pelo fototransistor foi substituído por sinal do próprio circuito eletrônico de ECG (sincronismo para cardioversão). A rede hospitalar de ar comprimido e vácuo foi substituída por uma bomba eletromagnética tipo pistão de duas fases (pressão e vácuo) que opera a volumes constantes e ajustáveis. Esse componente eliminou a válvula solenóide e o uso da câmara de segurança anterior ao cateter e passou a permitir o uso de diferentes fluidos gasosos para o bombeamento do cateter-balāo. Os circuitos de comutação e temporização continuaram os mesmos, exceto pelas modificações que foram necessárias nos estágios de potência e retificação. O diagrama esquemático da bomba eletromagnética encontra-se representado na Figura 3 . O diagrama em bloco de todo o sistema está representado na Figura 4 e o console que corresponde à atual bomba-balão está na Figura 5.

Com base no diagrama em bloco (Figura 4), o projeto concluído pode ser assim descrito:

A) Circuito sensor do sinal de cardioversāo. A cada ciclo cardiaco comuta o circuito temporizador no ramo ascendente da onda R do ECG.

B) Circuito temporizador. Permite a variação da largura de pulso de entrada em $A$ (unidade básica: circuito integrado $\mathrm{Cl}-555$ e transformadores de pulso).

C) Circuito de comutação de estágio de potência. Fornece a diferença de potencial elétrico necessária para funcionamento do próximo estágio, a partir do sinal cor- 
REIS, C. L.; ÉVORA, P. R. B.; BRASIL, J. C. F.; RIBEIRO, P. J. F.; OTAVIANO, A. G.; BONGIOVANI, H. L.; BOMBONATO, R.; FEREZ, M. A.; SGARBIERI, R. N.; MOREIRA NETO, F. F.; PEREIRA, A. S.; GOMES, P. - Desenvolvimento de um projeto para construção de bomba-balão para contrapulsação aórtica. Rev. Bras. Cir. Cardiovasc., 4(3): 210-219, 1989.

respondente à onda $R$ do ECG que entra em $A$ e tem sua duração ajustada em $B$ (unidade básica: tiristores).

D) Estágio de potência e circuito retificador. Ajusta o valor da diferença de potencial fornecida por $\mathrm{C}$ ao valor adequado para o funcionamento da bomba eletromagnética, bem como se encarrega de fornecê-la na forma de corrente contínua (unidades básicas: transformadores de tensão e pontes retificadoras).

E) Bomba eletromagnética. Tem por função o bombeamento do cateter-balão, permitindo insuflação e deflação do mesmo por deslocamento de volume por pistão (unidades básicas: eletro-imās).

F) Circuito e alarme. Sempre que o pistão da bomba eletromagnética parar em posição de manter o cateterbalāo insuflado (parada cardiocirculatória, desconexāo paciente-monitor, ausência do sinal na saída do monitor, etc.) por um periodo superior a três segundos, haverá o disparo de um sinal sonoro (unidade básica: circuito integrado $\mathrm{Cl}-555$ ).

G) Deflação manual. Permite a deflação do cateter a qualquer momento, independentemente do ciclo cardíaco. Deve ser acionada sempre que haja disparo do alarme sonoro. Serve, também, para aspirar o fluido gasoso desejado para a câmara de bombeamento.

H) Circuito "pulso interno". Gera um sinal de duração e forma semelhantes à saída de cardioversão do monitor, mas com freqüência regulável. Permite ciclar o balão na ausência de sinal eletrocardiográfico, o que permite utilizar a bomba para acionamento de sistemas produtores de fluxo pulsátil em circulação extracorpórea (unidade básica: circuito integrado $\mathrm{Cl}-555$ ).

O sinal correspondente à onda $R$ que entra no circuito sensor do sinal de cardioversão aciona todo o sistema de forma a manter o pistão da bomba eletromagnética em posição de deflação do cateter-balão pelo período correspondente à largura do pulso de saída do circuito temporizador. Após esse período, inicia-se a insuflação do cateter e, portanto, na ausência de sinal, o pistão pára na posição de insuflação.

Os blocos delimitados pela linha pontilhada, o diagrama da Figura 4, constituem os componentes básicos do projeto, em seu atual estágio.

Realizaram-se testes com o Protótipo III, para efeito de avaliação, principalmente dos tempos de início da deflação e final da mesma em relação à onda $R$ do ECG em duas situaçōes:

A) In vitro. Para estes testes, construiu-se um dispositivo que constou de uma coluna líqüida com $100 \mathrm{~cm}$ de altura, contida em tubo de P.V.C. com 10,2 cm de diâmetro, que foi envolvido, externamente, por uma folha de papel laminado, ao qual foi ligado um terminal para finalidade de conexão elétrica. Sobre a superfície da água, mas sem tóca-la, montou-se uma placa metálica

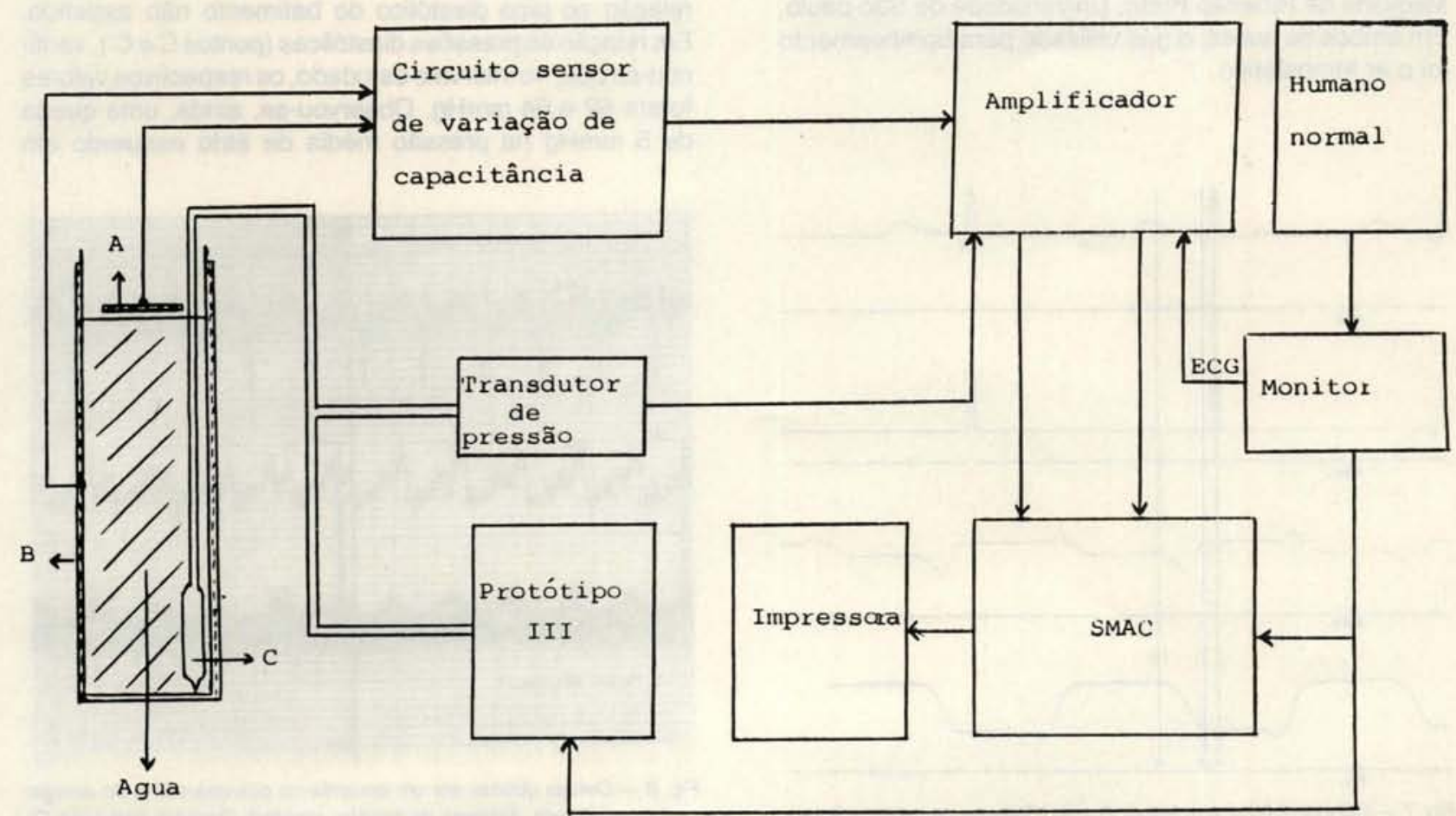

Fig. 6 - Diagrama esquemático do sisterna utilizado para testes in vitro. A e B: armaduras metálicas do capacitor no texto. 
REIS, C. L.; ÉVORA, P. R. B.; BRASIL, J. C. F.; RIBEIRO, P. J. F.; OTAVIANO, A. G.; BONGIOVANI, H. L.; BOMBONATO, R.; FEREZ, M. A.; SGARBIERI, R. N.; MOREIRA NETO, F. F.; PEREIRA, A. S.; GOMES, P. - Desenvolvimento de um projeto para construção de bomba-balão para contrapulsação aórtica. Rev. Bras. Cir. Cardiovasc., 4(3): 210-219, 1989.

de $9,5 \mathrm{~cm}$ de diâmetro, à qual também se ligou um terminal para conexāo elétrica. Entende-se, dessa maneira, que esse conjunto passou a constituir um capacitor em que as armaduras são, respectivamente, o papel laminado e a placa metálica, e o dielétrico a parede do tubo de P.V.C. e a água. O cateter-balão foi, então, introduzido até o fundo do tubo. A insuflação e a deflação do mesmo aproximam, ou afastam, a superfície do líqüido da placa metálica, o que provoca variaçāo na capacitância dos sistemas. Essa variaçāo, detectada por um circuito de capacitores em ponte, origina um sinal elétrico que, devidamente amplificado, usuou-se para excitar o sistema de registro (SMAC - Sistema Monitor Assistido por Computador T.E.B.). Dos cinco canais do sistema, utilizaram-se quatro, respectivamente para o registro de ECG proveniente de um monitor T.E.B., modelo $\mathrm{M}-10$, sinal de sincronismo para a bomba-balāo (saida de cardioversão do monitor de ECG), curva de pressão dentro do cateter-balão, obtidos através de um transdutor de pressão Bentley-Trantec, e curvas de variação de capacitância do dispositivo descrito. A impressora conectada ao SMAC foi a Grafix G S 1000 PC. O diagrama esquemático e em blocos dessa montagem experimental encontra-se representado na Figura 6.

B) In vivo. Em paciente submetido à cirurgia cardiaca para trocas valvares aórtica e mitral, que se encontrava assistido por contrapulsação aórtica pelo sistema AVCOKontron e com cateter-balāo de $40 \mathrm{~cm}^{3}$, realizaram-se registros. Utilizou-se um sistema Hewllett-Packard (HP-1064 C) de quatro canais pertencente à Disciplina de Cirurgia Torácica e Cardiovascular da Faculdade de Medicina de Ribeirão Preto, Universidade de São paulo. Em ambos os testes, o gás utilizado para bombeamento foi o ar atmosférico.

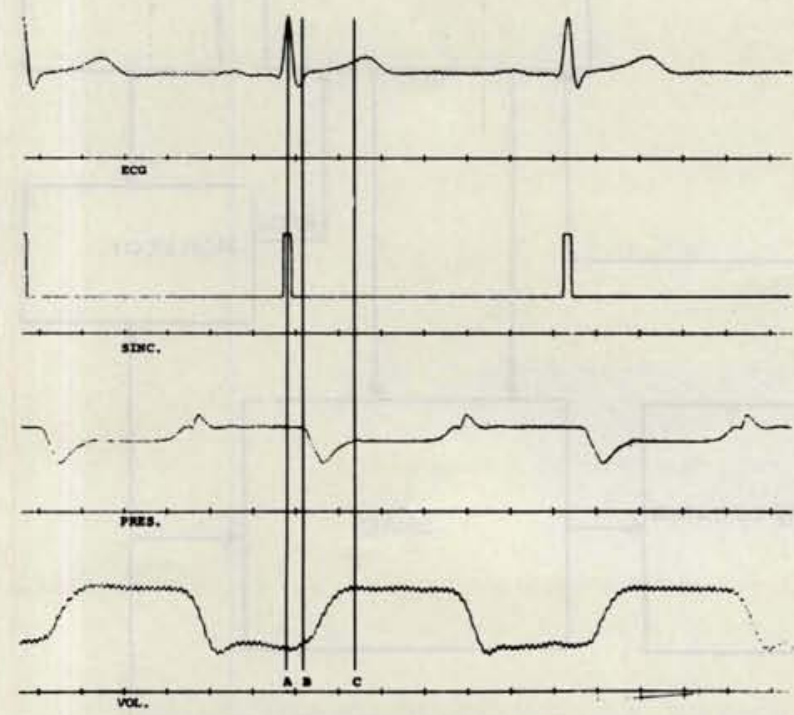

Fig. 7 - Curvas obtidas nos testes in vitro. Sistema de registro SmacT.E.B. (velocidade $-100 \mathrm{~mm} / \mathrm{s}$ ).

\section{RESULTADOS}

Apresentam-se, na Figura 7, os registros simultâneos do ECG, sinal de sincronismo da saida de cardioversāo do monitor, pressāo no cateter-balāo e volume deslocado pelo balão na coluna de água do sistema montado para os testes in vitro. A velocidade do registro foi de $100 \mathrm{~mm} / \mathrm{s}$. Os intervalos demarcados nas linhas sob as curvas representam 125 milesegundos (ms). As linhas verticais traçadas das curvas $(A, B, C$, destinamse a facilitar o estudo e as medidas das mesmas. $O$ intervalo $A B$, correspondente ao tempo do pico da onda $R$ ao início da deflaçāo do balão, foi de $45 \mathrm{~ms}$. O intervalo $\mathrm{BC}$, correspondente ao início da deflação e o seu final, foi de $150 \mathrm{~ms}$, tempo este que corresponde, portanto, ao tempo total da deflação do cateter-balão. O platô que se segue à deflaçāo corresponde ao equilibrio de pressões no cateter-balăo e no transdutor de pressão.

Apresentam-se, na Figura 8, os resultados obtidos no teste in vivo. Neste estudo, registraram-se, simultâneamente, o ECG, a pressão arterial média obtida na artéria radial esquerda, a pressão de átrio esquerdo e a pressão venosa central obtida na veia cava superior; a velocidade de registro foi de $25 \mathrm{~mm} / \mathrm{s}$. O ponto A corresponde ao pico sistólico, o B à incisura dicrótica, o C à pressāo diastólica, o ponto $A^{\prime}$ à pressão diastólica de pico do batimento assistido pelo Protótipo III e o C' à pressão diastólica final do batimento assistido. $\mathrm{O}$ início do bombeamento proporcionou a queda do pico sistólico (A) de $10 \mathrm{mmHg}$ em relação ao batimento não assistido, e o aumento do pico diastólico (A') de $12 \mathrm{mmHg}$ em relação ao pico diastólico do batimento não assistido. Em relação às pressões diastólicas (pontos $\mathrm{C} \mathrm{e} \mathrm{C}^{\prime}$ ), verificou-se que, no intervalo estudado, os respectivos valores foram 62 e $64 \mathrm{mmHg}$. Observou-se, ainda, uma queda de $5 \mathrm{mmHg}$ na pressão média de átrio esquerdo em

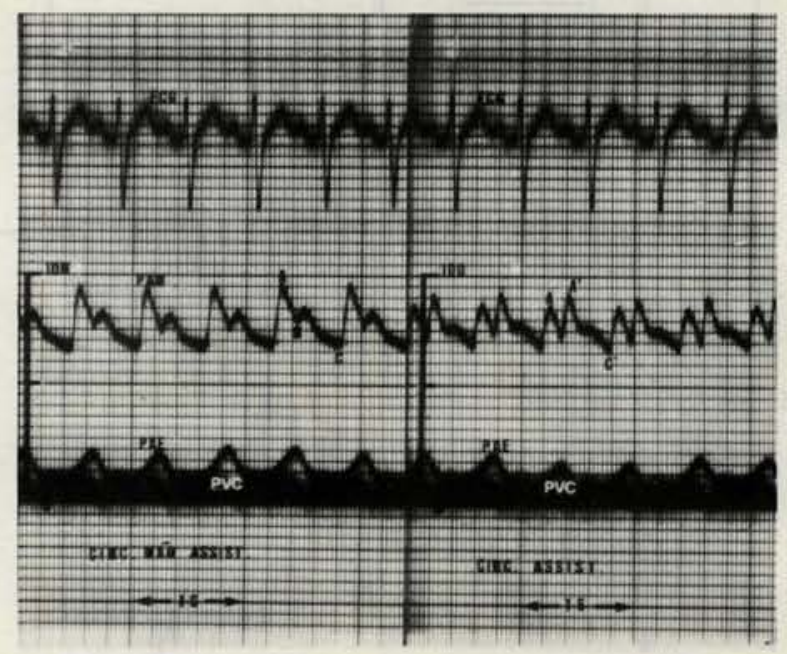

Fig. 8-Curvas obtidas em um paciente no pós-operatório de cirurgia cardiaca. Sistema de registro Hewllett- Packard (HP-1064 C) (velocidade $-25 \mathrm{~mm} / \mathrm{s}$ ). 
REIS, C. L.; ÉVORA, P. R. B.; BRASIL, J. C. F.; RIBEIRO, P. J. F.; OTAVIANO, A. G.; BONGIOVANI, H. L.; BOMBONATO, R.; FEREZ, M. A.; SGARBIERI, R. N.; MOREIRA NETO, F. F.; PEREIRA, A. S.; GOMES, P. - Desenvolvimento de um projeto para construção de bomba-balâo para contrapulsação aórtica. Rev. Bras. Cir. Cardiovasc., 4(3): 210-219, 1989.

batimentos assistidos, quando comparada com a pressão média de átrio esquerdo em batimentos não assistidos pela contrapulsação aórtica diastólica.

\section{DISCUSSĀO}

Assistência circulatória mecânica é a aplicação de qualquer dispositivo gerador de energia com o objetivo de melhorar ou substituir a função de um sistema circulatório ineficaz durante períodos variáveis.

A intenção de substituir a função de um órgão lesado ou insuficiente é uma atitude constante em todas as culturas, na história médica. Até a atualidade, têm-se testado não menos de 60 sistemas de assistência circulatória mecânica e, desses, só uns poucos têm tido aplicação sistemática, ressaltando-se o uso de dispositivos pulsáteis biventriculares, como ponte, em pacientes que aguardam transplante cardíaco, com bons resultados na manutenção temporária da circulação até, aproximadamente, três semanas. A contrapulsação com balão intraabrtico desenvolveu-se, simultaneamente, com a aplicação dos conceitos atuais de função ventricular e circulação periférica e com a cirurgia cardiovascular contemporânea. Como se mencionou na introdução deste trabalho, o balão intra-aórtico, apesar de suas limitaçōes, tem sido o único método ao alcance geral, com várias bombas disponiveis para sua realização. Utilizando seus princípios definidos por HARKEN, em 1958, que determinava os benefícios da contrapulsação aórtica diastólica,construíram-se as primeiras bombas que aspiravam sangue de uma artéria femoral durante a sístole e o reinfundiam na mesma artéria, ou na oposta, durante a diástole. Uma curta avaliação clínica, efetuada por Clauss, demonstrou que hemólise e o escasso incremento do fluxo coronário que ocorria em presença de uma hipotensão arterial eram fatores limitantes insuperáveis, aos quais se acrescentava o fato conhecido, determinado por Sarnoff, de que $o$ auxilio mecânico ao ventrículo esquerdo, por alívio de volume no compartimento de pós-carga, só se mostra eficaz se praticamente todo o sangue for desviado dessa câmara cardíaca. Esse princípio foi utilizado, em nossa Instituição, para contrapulsação aórtica intra-operatória, imediatamente após o término da circulação extracorpórea, com reais benefícios, por tempo determinado, até a recuperação adequada da funçāo ventricular do coração operado ${ }^{7}$.

Em 1962, MOULOPOULOS et alii ${ }^{4}$ construíram o primeiro modelo para contrapulsação com balão intraaórtico. $\mathrm{O}$ gás $\left(\mathrm{CO}_{2}\right)$ contido no interior de um balão de borracha siliconizada, que se posicionava no átrio aórtico, era mobilizado para o exterior e reinsuflado sincronicamente com ciclo cardíaco. Um console externo continha os sistemas pneumáticos, unidos ao balão intraaórtico por meio de um cateter e permitia ciclar suas válvulas solenóides com sinais derivados do ECG do paciente. Sete anos depois, Kantrowvitz publicou seus resultados no choque cardogênico. Desse momento até os dias de hoje, a prática tem evoluído intensamente e existe uma grande experiência clínica que respalda sua ampla difusão. Até 1979 , foram implantados mais de 40.000 balōes e calcula-se que mais de 200.000 pacientes tenham recebido esse tratamento, com ritmo anual de $\mathbf{5 0 . 0 0 0}$ pacientes por ano.

$\mathrm{Na}$ discussão do presente trabalho, as definiçōes, os conceitos e a síntese da evolução histórica apresentados tiveram o objetivo de estabelecer o estado da questão: assistência circulatória mecânica. $O$ texto utilizado para esta revisão, com algumas adaptaçōes, foi uma recente publicação de LIMA QUINTANA ${ }^{3}$, em 1987.

$\mathrm{Na}$ década de 70 , desenvolveu-se, o que foi, talvez, o primeiro projeto nacional, no Instituto Dante Pazzanese de Cardiologia, em São Paulo, projeto que se tornou uma dissertação de mestrado na Universidade Federal do Rio de Janeiro, apresentada por FARIAS ${ }^{2}$. Esse projeto teve, como sistema modelo comparativo, o utilizado na bomba balão Datascope System 80 . Foram encontradas, pela equipe envolvida no programa, dificuldades relativas à qualidade do material nacional, incluindo válvulas solenóides, compressores e bombas de vácuo. Um outro projeto desenvolveu-se, já na década de 80 , no Instituto do Coração do Hospital das Clínicas da Faculdade de Medicina da Universidade de São Paulo. Esse projeto também utilizou, como sistema modelo comparativo, o Datascope System 82 , sendo construído um protótipo, com pesquisas concomitantes, para o desenvolvimento do cateter-balão de poliuretano*. Esses sistemas diferem, fundamentalmente, do projeto aqui apresentado, por utilizar compressores, bombas de vácuo e válvulas solenóides para a insuflação e desinsuflação do cateter-balão, função esta desempenhada no Protótipo III por uma bomba eletromagnética tipo pistão.

O primeiro protótipo, desenvolvido em 1980, não representava, na verdade, uma bomba, mas sim um circuito eletropneumático divisor de fluxo. Esse sistema diferia do proposto por MOULOPOULOS ${ }^{4}$, basicamente, em dois aspectos: captação do sinal foto-elétricamente e na força motriz utilizada (vácuo e ar comprimido hospitalares). Os resultados experimentais obtidos com esse protótipo foram bastante proveitosos, porém três limitações significativas ficaram bem definidas: a) a vedação imperfeita dos orifícios da válvula solenóide, o que ocasionava variaçōes de pressão indesejáveis no cateterbalão; b) a dependência das linhas hospitalares de ar comprimido e vácuo que são, freqüentemente, instáveis: c) as inércias elétrica e mecânica do sensor foto-elétrico com LDR e da câmara de segurança (invólucro rígido com bulbo de látex), respectivamente, embora permitissem insuflação adequada, causavam breve retardo no início da deflação.

\footnotetext{
- Informação pessoal. Marina J. S. Maizato e Adib D. Jatene. Março de 1989.
} 
REIS, C. L.; ÉVORA, P. R. B.; BRASIL, J. C. F.; RIBEIRO, P. J. F.; OTAVIANO, A. G.; BONGIOVANI, H. L.; BOMBONATO, R.; FEREZ, M. A.; SGARBIERI, R. N.; MOREIRA NETO, F. F.; PEREIRA, A. S.; GOMES, P. - Desenvolvimento de um projeto para construção de bomba-balão para contrapulsação aórtica. Rev. Bras. Cir. Cardiovasc., 4(3): 210-219, 1989.

Em 1986, retomaram-se as pesquisas desenvolvendo-se o segundo protótipo. Neste, superaram-se parcialmente duas das três dificuldades anteriormente citadas. Manteve-se o mesmo circuito eletropneumático divisor de fluxo apenas com três diferenças: a) utilização de uma válvula solenóide de três vias, agora disponível comercialmente, que oferecia uma excelente vedação; b) a câmara de segurança foi redesenhada, diminuindo-se ao mínimo o seu espaço-morto e substituindo-se o bulbo de látex por um balão de poliuretano de paredes mais flexíveis, com a finalidade de diminuiçāo da inércia do sistema; c) o sensor foto-elétrico LDR foi substituído por um fototransistor convencional com velocidade de resposta muito maior. Com esse protótipo, conseguiram-se excelentes curvas de pressão, compatíveis, hemodinâmicamente, em termos experimentais, com o desejado na contrapulsação. Deparou-se, no entanto, com uma dificuldade inesperada: com cateteres-balão usuais para contrapulsação no humano ( 30 e $40 \mathrm{~cm}^{3}$ ), observou-se, novamente, um retardo inadequado da deflação, fato este que foi atribuido aos pequenos diâmetros dos orificios de fluxo de válvula solenóide. Tal efeito foi, acentuadamente, minimizado com a insuflação e deflaçāo do cateter sem a câmara de segurança, verificando-se que esta, mesmo redesenhada, mantinha-se inadequada para volumes maiores ${ }^{2}$.

Após esssa etapa, muito proveitosa do ponto de vista de aprendizado, o projeto evoluiu para a construçāo do terceiro protótipo, que é o objetivo principal desta comunicaçāo. Um grave avanço foi a substituição do sinal sistólico captado pelo fototransistor por um sinal interno do próprio circuito eletrônico do monitor de ECG. Os esforços foram concentrados no sentido de eliminar-se a rede hospitalar de ar comprimido e vácuo, optando-se pela construçāo de uma bomba eletromagnética. As bombas compressoras e de vácuo foram avaliadas e descartadas, pelo aumento do porte final do dispositivo, nivel de ruído e inércia do sistema. Esse componente eliminou a válvula solenóide e o uso da câmara de segurança anterior ao cateter, bem como permitiu o uso de diferentes fluídos para o bombeamento do cateter-balão. Os testes mostraram que essa bomba é estável e eficiente, após longos períodos de pulsação ininterruptos. Além disso, acoplou-se aos circuitos de comando um oscilador, para gerar sinais que acionam a bomba, independentemente dos sinais do ECG. Essa modificação teve a finalidade de utilizaçăo da bomba-balão para a obtenção de fluxo pulsátil em circulação extracorpórea, por meio da sua conexão ao dispositivo pulsador, em substituição ao sistema mecânico até então utilizado em nosso Serviço ${ }^{5.6}$. Permitiu, também, assegurar com eficiência a contrapulsação pós-perfusional intra-operatória através da cânula de perfusão aórtica ${ }^{7}$.

Os testes in vitro demonstraram uma insuflação bastante adequada do cateter-balāo e um ligeiro retardo na fase de desinsuflação. Os resultados obtidos nas ob- servaçōes em humano foram animadores, ressaltandose que a ligeira diferença encontrada nas pressões diastólicas finais (62 e $64 \mathrm{mmHg}$ ), nos batimentos não assistidos, era esperada. Um dos objetivos do auxilio mecânico por contrapulsação é, além de melhorar a perfusão coronariana, diminuir a pressão diastólica final por diminuição da pós-carga ventricular esquerda. Investigaram-se as possiveis razões pelas quais esse objetivo nāo foi alcançado, concluindo-se que isso ocorre pelo motivo de que a deflaçāo do balão, embora tenha seu início em tempo adequado, nāo se completa no tempo desejado. Existem várias razōes possiveis que, se consideradas em conjunto, poderão melhorar o desempenho do protótipo III. Assim é que, no prosseguimento das tentativas para a correção do problema, delinearam-se os seguintes procedimentos a serem realizados: a) testar o sistema utilizando-se gás hélio para bombeamento do balão, com finalidade de diminuição da inércia; b) diminuir o comprimento do cateter que liga a bomba ao balāo; c) aumentar a tensão de alimentação do eletro-ímã que traciona o pistão da bomba eletromagnética, aumentando-se, portanto, o campo magnético gerado pela bobina e traçāo; d) modificar o sistema eletrônico que comanda a bomba, passando-se a utilizar uma lógica de três estados (lógica pressão-exaustão) combinada com a atual (lógica exaustão-pressão); e) acoplar ao sistema de alarme um circuito eletrônico que permita a imediata deflação do balão, sempre que ele permaneça insuflado por mais de três segundos. Os estudos preliminares mostraram que essas alteraçōes podem ser realizadas com relativa facilidade e serāo objeto de experimentos e comunicaçōes futuras. O sistema de monitorização da bomba-balāo já está desenvolvido.

Finalmente, deve-se enfatizar o motivo que levou à apresentação deste trabalho, no 16: Congresso Nacional de Cirurgia Cardiaca. Este projeto motivou a criação do Setor de Bioengenharia do Hospital do Coração de Ribeirão Preto. Embora já se tenham passados oito anos, desde o seu início, ele cumpriu o seu objetivo de desenvolver conhecimentos, que permitiram a expansão de outros projetos, hoje concluídos sob a forma de sistemas e aparelhos em uso clínico.

Todo projeto em Bioengenharia concluido deve ser transformado em equipamento de uso clínico ou de pesquisa, para que se cumpra o seu objetivo maior. Porém, deve-se ressaltar o seu aspecto relacionado ao ensino e à pesquisa, uma vez que médicos em treinamento na Instituiçāo têm acesso ao desenvolvimento. Nesse aspecto, todos os esforços dispendidos têm deixado, no conjunto, um saldo positivo bastante gratificante, que estimula a conclusão do projeto em questão e a saudável ambição do desenvolvimento de outros projetos, sempre voltados para a triade assistência, ensino e pesquisa, fundamental para o pleno desenvolvimento de Instituiçōes relacionadas com a Medicina, princípio este enfatizado na introdução deste texto. 
REIS, C. L.; ÉVORA, P. R. B.; BRASIL, J. C. F.; RIBEIRO, P. J. F.; OTAVIANO, A. G.; BONGIOVANI, H. L.; BOMBONATO, R.; FEREZ, M. A.; SGARBIERI, R. N.; MOREIRA NETO, F. F.; PEREIRA, A. S.; GOMES, P. - Desenvolvimento de um projeto para construção de bomba-balāo para contrapulsação aórtica. Rev. Bras. Cir. Cardiovasc., 4(3): 210-219, 1989.

RBCCV 44205-95

REIS, C. L.; ÉVORA, P. R. B.; BRASIL, J. C. F.; RIBEIRO, P. J. F.; OTAVIANO, A. G.; BONGIOVANI, H. L.; BOMBONATO, R.; FEREZ, M. A.; SGARBIERI, R. N.; MOREIRA NETO, F. F.; PEREIRA, A. S.; GOMES, P. - Development and construction of a balloon-pump for aortic counterpulsation.. Rev. Bras. Cir. Cardiovasc., 4(3): 210-219, 1989.

ABSTRACT: The present paper presents the project and construction of a balloon-pump for aortic counterpulsation. Three experimental models were developed, the first two using hospital air and vacuum lines for inflation and deflation of the balloon catheter. These two inicial models differes among themselves in the mechanism used to capture the light signal corresponding to the R wave of the ECG, which was used to sincronize the pumping. The solenoid valve and electronic components were of higher resolution in the second model. The third and present model recieves the $\mathrm{R}$ wave signal from the cardioversor adaptor of ECG monitor and the hospital vacuum and air lines along with the solenoid valve were substituted by an electromagnetic pump. The problems related to late deflation that have ocurred in the system are still in study. Emphasis is given on the importance of this research, which has incremented knowledge for the construction of other medical equipment, mainly in the area of respiratory care.

DESCRIPTORS: aortic balloon-pump; counterpulsation; assisted circulation, mechanic.

\section{REFERÊNCIAS BIBLIOGRÁFICAS}

1 ÉVORA, P. R. B.; REIS, C. L.; RIBEIRO, P. J. F.; BRASIL, J. C. F.; BOMBONATO, R.; FEREZ, M. A.; MOREIRA NETO, F. F. - Apresentação de módulo ECG-sincronizado para contrapulsaçâo aórtica. Atual. Cardiol. (SOCESP), 3: 6, 1988. (Resumo). Apresentado ao Congresso Paulista de Cardiologia do Estado de Sāo Paulo. Ribeirão Preto, SP, 1988.

2 FARIAS, R. A. C. - Aspectos biomecânicos de um sistema de contrapulsaçẫo com balāo intraórtico. Rio de Janeiro, 1976. [Dissertação. Mestrado - Universidade Federal do Rio de Janeiro].

3 LIMA QUINTANA, O. - Asistência circulatória: una visión actual de la contrapulsación con balón intraórtico. In: KAPLAN, N. M. \& FELDSTEIN, C. A. Terapéutica cardiovascular. Buenos Aires, Editorial Médica Panamericana, 1987. p. 321-346.

4 MOULOPOULOS, S. D.; TCPAZ, S.; KOLFF, W. J. - Diastolic balloon pumping (with carbon dioxide) in the aorta: mechanical assistance to the failing circulation. $A m$. Heart J., 63: 669-675, 1962.

5 REIS, C. L.; ÉVORA, P. R. B.; RIBEIRO, P. J. F.; BRASIL, J. C. F.; OTAVIANO, A. G.; BONGIOVANI, H. L.; MARGARIDO, E. A.; - Fluxo pulsátil em circulação extracorpórea (CEC): apresentaçāo de um sistema mecânico com estudos preliminares hemodinâmicos e do transporte de oxigênio. Arq. Bras. Cardiol., 43: 239-244, 1984.

6 REIS, C. L.; ÉVORA, P. R. P.; RIBEIRO, P. J. F.; BARSIL, J. C. F.; OTAVIANO, A. G.; BONGIOVANI, H. L.; BOMBONATO, R.; - A simple mechanical system for pulsatile cardiopulmonary bypass. J. Cardiovasc. Surg. (Torino), 32: 143-144, 1987.

7 REIS, C. L.; ÉVORA, P. R. B.; RIBEIRO, P. J. F.; BRASIL, J. C. F.; OTAVIANO, A. G.; BONGIOVANI, H. L.; BOM-
BONATO, R.; PEREIRA, A. S. - Contrapulsaçāo aórtica pós-circulação extracorpórea (CEC): apresentação de método. Rev. Bras. Cir. Cardiovasc., 1: (2): 29-33, 1986.

AGRADECIMENTOS: Os autores agradecem ao $\mathrm{Sr}$. João Inácio dos Reis, pelos ensinamentos, constante incentivo e confecçōes de componentes mecânicos. Ao Prof. João José Carneiro, pelo estudo hemodinâmico realizado.

\section{Discussão}

\section{DR. HÉLIO PEREIRA MAGALHÃES São Paulo, SP}

Agradeço o convite para comentar este trabalho e me congratulo com a Comissão Organizadora, por ter propiciado que o trabalho completo tenha chegado às nossas mãos, para melhor análise do material. Inicialmente, parabenizo os autores por mais uma contribuição na área da circulação assistida no Brasil. Sobre o trabaIho em si, apesar de muito importante, o considero ainda num estágio prematuro para ser apreciado e discutido neste tipo de congresso. Como o projeto ainda está em fase de desenvolvimento, melhor seria discuti-lo em congresso de Bioengenharia, para busca da solução do problema ainda pendente, levantado pelo autor. Apesar disso, procurei analisar o aparelho, para dar alguma contribuição, mas faltam dados técnicos, principalmente um desenho em escala da bomba, potência eletromagnética e curso do pistão, porém creio que o problema de deflação esteja relacionado com esses três ítens. No teste in vitro, entendo que as linhas $\mathrm{AB}$ compreendam a fase de contração isométrica e as linhas $\mathrm{BC}$ correspondam ao período de expulsão rápida do ventrículo, alcançando 
REIS, C. L.; ÉVORA, P. R. B.; BRASIL, J. C. F.; RIBEIRO, P. J. F.; OTAVIANO, A. G.; BONGIOVANI, H. L.; BOMBONATO, R.; FEREZ, M. A.; SGARBIERI, R. N.; MOREIRA NETO, F. F.; PEREIRA, A. S.; GOMES, P. - Desenvolvimento de um projeto para construção de bomba-balão para contrapulsação aórtica. Rev. Bras. Cir. Cardiovasc., 4(3): 210-219, 1989.

o pico máximo de pressão dentro da aorta na linha $\mathrm{C}$. A curva de pressão do balão mostra uma queda abrupta e, depois, um retorno parcial até $150 \mathrm{~ms}$, depois segue um plateau de $25 \mathrm{~ms}$, sem alcançar a linha de base, e estes eventos da curva de pressão deveriam ser identificados e, inclusive, fazer a curva do aparelho AVCO no mesmo esquema in vitro para correlação. No registro feito in vitro, existe uma correlação aproximada e esperada entre o pico de pressão e o pico da onda $T$, com leve retardo de $20 \mathrm{~ms}$ em circulaçāo não assistida e, quando entra a circulação assistida pelo protótipo, esse retardo aumentou para cerca de $60 \mathrm{~ms}$. Esses eventos deveriam ser melhor comentados pelo autor e, até, colocar na mesma figura o registro com o aparelho AVCO, para podermos analisar comparativamente as três curvas. Gostaria que este trabalho voltasse, futuramente, a este congresso, com seus problemas técnicos resolvidos e com casuística experimental e clínica suficiente para podermos apreciar e discutir as indicaçōes, as complicaçōes e os resultados finais.

\section{ENG: JOSÉ FRANCISCO BISCEGLI}

São Paulo, SP

Nossa experiência, do grupo de Engenharia Biomédica do Instituto Dante Pazzanese de Cardiologia, que, na década de 70 , desenvolveu e testou um modelo de bomba-balão intra-aórtico, baseia-se nas pesquisas e protótipos que geraram as teses dos Engenheiros Rodrigo Araês Caldas Farias e Ivan Kyanitza. Fazemos referências a dois aspectos: 1) sobre a idéia da construção a bomba em si; 2) sobre a apresentação na "Revista Brasileira de Cirurgia Cardiovascular". Primeiro aspecto: Não entraremos no mérito da discussão da utilidade do aparelho, dentro dos objetivos que os autores especificam. A utilidade e a aplicação estão experimentadas e comprovadas, bem como a inutilidade do sistema bomba-balāo em aplicações outrora consideradas úteis. A nossa opiniāo sobre a idéia de se construir uma bombabalāo para contrapulsaçāo aórtica, através da utilizaçāo de uma bomba eletromagnética tipo pistão de duas fases, é que ela é extremamente interessante e enriquecedora, pois é uma novidade e demonstra criatividade e objetividade, tendo, inclusive, eliminado o uso de componentes, como compressores, aspiradores, válvulas, etc., que apresentavam problemas de confiabilidade. Segundo aspecto: 1) A forma de apresentação do projeto que, do ponto de vista da Engenharia Biomédica, não se pode usar o termo pressão negativa, que não tem nexo em Engenharia. Dentro dos estudos de pressāo, pode-se falar em pressão abaixo ou acima de uma pressão referencial positiva, mas nunca abaixo de zero, ou seja, negativa. 2) Sobre o circuito sensor de cardioversāo que comuta o circuito temporizador no ramo ascendente da onda R do ECG a cada ciclo cardíaco, nāo temos informaçōes se ele vai comutar no próximo ciclo, ou no ciclo em que ele detecta a onda R. 3) Quanto ao circuito de alarme, que avisa, sempre que o pistão da bomba eletromagnética parar em posiçāo de balão insuflado, achamos estranho o fato do circuito não ser concebido de forma a que sempre o pistão volta para uma posiçāo de deflação de balão, quando das condiçōes críticas citadas (como parada cardiocirculatória, desconexão paciente-monitor, ausência de sinal de saída dos monitores, etc.). Isto nāo foi previsto? Não foi possível fazê-lo? Seria necessário um plantonista que, ao sinal de alarme, liberasse o balāo? 4) Fizeram-se testes em pacientes humanos. Por que não se testou em animais? $\mathrm{O}$ ar atmosférico usado era livre de umidade e microorganismo? Caso positivo, como fizeram? E se, num acontecimento não incomum, o balāo tivesse vazado? Qual a segurança nos testes? 5) $\mathrm{Na}$ discussão do trabalho escrito, existe toda uma recapitulação histórica, que caberia mais apropriadamente na introduçāo do trabalho. 6) No preâmbulo da discussão, temos uma falha que reputamos grave, na definição do que seja assistência circulatória mecânica. Não acreditamos que ela seja capaz de substituir a função de um sistema circulatório. Achamos que ela seja capaz de substituir uma determinada função de um órgão do sistema circulatório e, eventualmente, no progresso da Engenharia Biomédica, todo um órgão, mas nunca um sistema. 7) Como último comentário, temos uma estranha observação sobre "inércia e mecânica do sensor foto-elétrico com LDR e da câmara de segurança". Sabemos que a inércia do LDR é desprezível, face aos tempos envolvidos nos mecanismo do aparelho. Apesar das críticas, que reputamos construtivas, cabe-nos louvar o trabalho como um todo, já que as observaçōes e críticas feitas são facilmente sanáveis e os aspectos positivos do trabalho merecem nossos cumprimentos.

\section{DR. REIS}

(Encerrando)

Gostariamos de expressar nossos agradecimentos aos comentadores oficiais deste trabalho, Engenheiro José Francisco Biscegli e o colega Hélio Pereira MagaIhães. Agradecemos, também, aos colegas Domingos Marcolino Braile, Marcos Ramos Carvalho e Euclides Marques, cujas opiniōes, sugestōes e comentários são sempre enriquecedores. Ao Engenheiro Biscegli, cujo empenho no desenvolvimento de equipamentos médicos, principalmente na área de Cardiologia Cirúrgica, há muito conhecemos, gostaríamos de dizer o seguinte: 1) Aceitamos, sem contestaçāo, a crítica quanto à inadequação do termo "pressāo negativa", que, sem dúvida, não tem significado em Física. Teria sido melhor se tivéssemos utilizado o termo "sucção", em lugar dele. 2) 0 sinal retirado da saída de cardioversão do monitor comuta o circuito temporizador no mesmo ciclo, e não próximo. Conforme o exposto na Discussão deste trabalho, utilizamos a lógica "exaustão-pressāo", numa tentativa de simplificar a construção e o sincronismo da bomba (variação 
REIS, C. L.; ÉVORA, P. R. B.; BRASIL, J. C. F.; RIBEIRO, P. J. F.; OTAVIANO, A. G.; BONGIOVANI, H. L.; BOMBONATO, R.; FEREZ, M. A.; SGARBIERI, R. N.; MOREIRA NETO, F. F.; PEREIRA, A. S.; GOMES, P. - Desenvolvimento de um projeto para construçāo de bomba-balão para contrapulsação aórtica. Rev. Bras. Cir. Cardiovasc., 4(3): 210-219, 1989.

da freqüência cardíaca e arritmias). $\mathrm{O}$ uso desta lógica, entre outros fatores, tem sido a causa de nossas dificuldades, na resolução do problema dos atrasos observados na deflaçāo da câmara de cateter-balão. 3) Com relação ao fato do balão parar insuflado na ausência de sinal (onda R), o mesmo sinal que comuta o sistema de alarme pode, sem qualquer dificuldade técnica, comutar o circuito de comando de solenóide de tração da bomba eletromagnética. Isto, evidentemente, foi previsto e será modificado no protótipo atual. Embora, na Discussão deste trabalho, se faça referência a testes experimentais apenas com o Protótipo II, gostariamos de salientar que também os Protótipos I e III foram submetidos a estes testes. $\mathrm{O}$ ar atmosférico utilizado na câmara de bombeamento foi introduzido na mesma após passagem por filtro de bronze sinterizado. Esclarecemos, também, que o volume introduzido na câmara de bombeamento, ao preencher a câmara do cateter-balāo, eleva a pressão na mesma a $120 \mathrm{mmHg}$ sob pressão atmosférica, valor muito inerior ao necessário para sua rotura no cateter-balão utilizado. Quanto à falha apontada na definição de Assistência Circulatória Mecânica, afirmamos que a mesma deveu-se a um deslize na revisão do texto, tanto que se encontra praticamente corrigida no parágrafo seguinte. Finalmente, devido à lógica utilizada nos Protótipos I e II (a mesma do Protótipo III), no Protótipo II procuramos empregar componentes com maior velocidade de resposta, razão pela qual decidimos pelo uso de fototransistor como sensor foto-elétrico. Ao colega Hélio Pereira, que já forneceu contribuições inestimáveis à Cirurgia Cardíaca, respondemos a seguir. Sem dúvida o Protótipo III da nossa bomba balão intraaórtico necessita completar seu desenvolvimento. $\mathrm{O}$ ob- jetivo deste trabalho, contudo, foi o de enunciar as dificuldades e os problemas existentes em nosso meio, para realização de um projeto como este e, ao mesmo tempo, demonstrar os resultados que obtivemos. Sua apresentação, como propõe o colega, em um congresso de Bioengenharia, poderia trazer outras sugestōes de grande valia. Os dados técnicos descritivos da Bomba Eletromagnética desenvolvida foram omitidos, numa tentativa de tornar menos enfadonha a apresentação deste trabalho em um congresso médico; porém com satisfação os forneceríamos ao colega, para sua melhor avaliação posterior. Infelizmente, não nos foi possivel, com a bomba AVCO-Kontron, realizar os mesmos testes que realizamos com a nosssa, pelo fato de não dispormos da referida bomba no local onde os testes ocorreram. Concordamos em que isto seria de grande utilidade para comparação. Quanto ao traçado in vivo, os picos sistólicos posicionam-se da mesma maneira em relação ao ECG, tanto no pulso assistido como no não assistido. Já o pico diastólico gerado pela contrapulsação (creio ser a este que o colega se refere), terá sua posição determinada pelo ajuste do circuito de temporização, que, em última análise, irá comandar o início do período de insuflaçăo do cateter balão, o que, como é sabido, considerando-se o traçado obtido pela artéria radial, deverá ocorrer $50 \mathrm{~ms}$ antes da incisura dicrótica. A breve duração do teste in vivo não nos permitiu obter traçados com diferentes ajustes do circuito temporizador. Agradecendo, novamente, a todas as críticas, sugestōes e opiniōes apresentadas, reafirmamos nossa intençăo de considerá-las com grande apreço, no desenvolvimento final deste projeto. Obrigado. 